\title{
Aprendizagem Baseada em Problemas no Internato: Há Continuidade do Processo de Ensino e Aprendizagem Ativo?
}

\author{
Problem-Based Learning in Internship: \\ Is There Continuity of the Active \\ Teaching-Learning Process?
}

\author{
Ricardo Correa Ferreira \\ Hissachi Tsujill \\ Silvia Franco Rocha Tonhom ${ }^{I I}$
}

\section{PALAVRAS-CHAVE \\ - Educação Médica; \\ - Internato e Residência; \\ - Aprendizagem Baseada em Problemas.}

\section{KEYWORDS}

- Medical Education;

- Medical Staff;

- Problem-Based Learning.
Reencaminhado em: 29/01/2014

Reencaminhado em: 28/07/2014

Aprovado em: 10/03/2015
Problem-Based Learning (PBL) contributes to the active search for necessary information and skills for professional internship training. This study aimed to estimate how Famema medical students and their preceptors understand the active learning process in the construction of knowledge in internship activities. A qualitative study was conducted with groups of interns and preceptors, who were interviewed for data collection. Content analysis was applied and three empirical categories common to students and preceptors were found as a result: a) the preceptors' pedagogical action in constructing the interns' knowledge - their commitment to maintaining dialogue; $b$ ) the influence of setting, the patients and pedagogical actions on the teaching and learning processes in the preceptorship; and c) PBL and the Famema internship - the reflection of the active pedagogical process in knowledge construction and student training. These categories demonstrated the difficulty in continuing the active learning process. 


\section{INTRODUÇÃO}

O ensino médico, nas últimas décadas, vem passando por um processo de ampla rediscussão quanto à necessidade de formar profissionais voltados à resolução dos problemas de saúde dos indivíduos e da comunidade, visto que o modelo de ensino tradicional, pautado na transmissão dos conhecimentos, não colabora para a formação médica condizente com o perfil de profissional desejado.

$\mathrm{Na}$ formação tradicional, o estudante torna-se dependente de seus docentes na aquisição de novos conhecimentos e mantém uma postura essencialmente passiva na construção de seus saberes. Surgem, então, movimentos de mudança na formação desses profissionais, como o proposto pelas Diretrizes Curriculares Nacionais (DCN) do curso de Medicina, em 2001, que ressaltam a importância de adotar currículos que priorizem processos de ensino e aprendizagem centrados no estudante, como a Aprendizagem Baseada em Problemas (ABP), e voltados para a construção ativa do conhecimento e as necessidades de saúde da população.

No currículo do curso de Medicina da Faculdade de Medicina de Marília (Famema), utiliza-se a ABP, que contribui efetivamente para a busca ativa de informações e habilidades necessárias à formação profissional durante a graduação, inclusive no internato.

Nota-se, porém, que a postura passiva de internos e as ações pedagógicas tradicionais dos preceptores não têm contribuído satisfatoriamente para a construção ativa do conhecimento no internato. Logo, é importante avaliar se o currículo e o processo pedagógico preconizados pela Famema estão sendo implementados na quinta e sexta séries do curso, tendo em vista que a descontinuidade do processo pedagógico pode prejudicar a formação deste futuro profissional, assim como o investimento que a instituição vem realizando desde 1997 com sua mudança curricular.

\section{O internato médico e seu processo de ensino e aprendizagem}

No começo do século XIX, na França, os egressos e licenciados em Medicina habilitados para exercer a profissão eram admitidos em um hospital qualificado para desempenhar a função de clínico geral (médico que tratava primariamente) sob a orientação de um chefe, o maître de service. Para exercer esta função, o egresso que morava no hospital era chamado de interne de hospitaux ${ }^{1}$.

Nos Estados Unidos, a primeira escola de Medicina, o College of Philadelphia, fundado em 1765, seguiu quase estritamente a Escola de Edimburgo, na ocasião a melhor escola de Medicina clínica da Europa, e a única com ensino tutorial, mais próximo do enfermo. Posteriormente, o ensino da Me- dicina nos Estados Unidos foi sucessivamente influenciado pela escola francesa, na primeira metade do século XIX, e pelas escolas austríacas e alemãs, na segunda metade desse século ${ }^{1}$.

Por influência dessas duas escolas, a maioria das escolas médicas minimizou a formação prática, enfatizando um aprendizado quase exclusivamente teórico e "científico". Os egressos dessas escolas, sentindo necessidade de uma formação prática ao término do curso, procuravam hospitais em que havia algum clínico de renome, para conseguirem, na qualidade de aprendizes, maior capacidade de desempenho ${ }^{1}$.

Esses profissionais constituíam uma mão de obra pouco onerosa para os trabalhos menores de que os enfermos necessitavam e eram chamados de house staff. Em alguns hospitais, esses profissionais moravam no local e eram chamados de "internos". Na América Latina, embora o ensino clínico em hospitais tenha sido incorporado desde 1920 aos últimos anos de formação médica, foi na década de 1950 que a maioria das escolas de Medicina o estabeleceram como requisito prévio à diplomação do estudante ${ }^{1}$.

No Brasil, o internato ou estágio curricular obrigatório médico, inicialmente instituído pela Resolução $\mathrm{n}^{\circ}$ 8, de outubro de 1969, parecer 506/69 do Conselho Federal de Educação (CFE), foi conceituado como o período do término da graduação médica em que as escolas médicas eram obrigadas a estabelecer em seus currículos um período obrigatório de ensino prático, no qual os estudantes deveriam receber treinamento intensivo contínuo, sob supervisão docente, em instituição de saúde vinculada ou não à escola médica ${ }^{2}$.

Com essa resolução, os objetivos do internato médico eram os seguintes: representar a última etapa de formação escolar do médico geral, com a capacidade de resolver ou bem encaminhar os problemas de saúde dos pacientes a serem atendidos; promover o aperfeiçoamento ou a aquisição de atitudes adequadas à assistência ao doente e permitir experiências em atividades que integrassem a escola médica e a comunidade ${ }^{2,3,4}$.

O internato tinha também como objetivos: estimular o estudante a preservar a saúde e prevenir as doenças, oferecer oportunidade para o estudante ampliar e integrar os conhecimentos adquiridos antes do curso médico, desenvolver nos estudantes deveres éticos, assim como estimulá-los a se aperfeiçoar de forma permanente $e^{2,3,4}$.

Em maio de 1983, o CFE publicou a Resolução n⿳ำ 9, que conceituava o internato como o último ciclo do curso médico, livre de disciplinas acadêmicas, com treinamento intensivo, contínuo, sob supervisão docente em instituição de saúde vinculada ou não a uma Instituição de Ensino Superior (IES) ${ }^{2}$. 
Propôs-se, como um dos objetivos principais, a formação de um médico geral. Nesta fase de aprendizado, o estudante deveria ampliar, integrar e aplicar conhecimentos adquiridos nos ciclos anteriores (ciclo básico e pré-clínico), com o objetivo de desenvolver técnicas e habilidades indispensáveis ao exercício dos atos médicos básicos ${ }^{2}$.

A organização do internato também foi regulamentada por essa mesma resolução, que resultou em um Manual do Internato do MEC. Este previa como áreas de estágio a Pediatria, Clínica Médica, Ginecologia e Obstetrícia, e Cirurgia, devendo se estender por dois a quatro semestres, com carga horária total mínima de 1.800 horas $^{2,3,4}$.

Até 2001, quando foi publicada a Resolução CNE/CES (Câmara de Educação Superior/Conselho Nacional de Educação) no 4, o internato tinha como orientação apenas o contido na Resolução CFE/MEC nº 9, de maio de 1983. Em 2001, o internato deixou de ter uma orientação nacional detalhada e passou a constar em apenas um artigo e um parágrafo na Resolução $n^{-0} 4 / 2001$ das DCN $^{5,6}$.

O internato foi a parte da formação médica de graduação que teve um tratamento mais superficial nas DCN de 2001. Foi chamado de estágio curricular obrigatório de treinamento em serviço, em regime de internato, tendo sido definidos apenas elementos de estrutura mínima, como a etapa integrante da graduação, estágio curricular obrigatório de treinamento em serviço, em serviços próprios ou conveniados, sob supervisão direta dos docentes da própria escola/faculdade, com a carga horária mínima do estágio curricular atingindo 35\% da carga horária total do curso de graduação em Medicina ${ }^{7,8}$.

Segundo as DCN de 2001, o internato deve incluir aspectos essenciais nas áreas de Clínica Médica, Cirurgia, Ginecologia-Obstetrícia, Pediatria e Saúde Coletiva, com atividades no primeiro, segundo e terceiro níveis de atenção em cada área, cujas cargas horárias teóricas não ultrapassassem 20\% do total por estágio, realizado em instituições próprias ou conveniadas que mantivessem programas de residência médica ${ }^{7,8}$.

\section{O internato na Famema}

Na Famema, o internato contempla os estágios curriculares sugeridos pelas DCN. As diferentes disciplinas foram integradas em estágios de Saúde Materno-Infantil, Saúde do Adulto, Urgência e Emergência, Eletivo, articulados com as disciplinas de Saúde Coletiva e Saúde Mental ${ }^{9,10}$.

O modelo pedagógico vigente na Famema é centrado no estudante e baseado no paciente, utilizando os princípios da educação de adultos, sendo orientado por competência e com integração da dimensão biopsicossocial. De forma adaptada ao internato, utiliza a ABP, que é uma forma de educação em que os conhecimentos necessários ao exercício da profissão são adquiridos no mesmo contexto em que serão usados pelos estudantes em formação. Os conteúdos das diferentes disciplinas são estudados de forma articulada, baseados nas necessidades de saúde dos pacientes ${ }^{9}$.

No internato, o Problema da ABP passa a significar Paciente, e não um Problema de Papel. Esse processo de ensino e aprendizagem centrado nos estudantes os torna mais ativos, independentes, criativos, críticos, cooperativos, capazes de avaliar seus progressos, com desenvolvimento de boa capacidade de comunicação, relacionamento interpessoal, atitudes e técnicas para continuar aprendendo ao longo da vida ${ }^{9}$.

O processo de ensino e aprendizagem, nesse momento do internato, é centrado no paciente e realizado com a integração das diversas dimensões do ser humano, contribuindo para despertar o interesse dos estudantes, visando à formação de médicos mais preocupados em cuidar não somente da doença, mas, sim, de todas as necessidades do paciente ${ }^{9}$.

O Manual do Internato da Famema ${ }^{9}$ preconiza a adaptação dos passos da ABP, com os seguintes momentos das discussões: apresentação e discussão da anamnese e exame físico, com os aspectos biopsicossociais, identificando e integrando os dados relevantes com vistas ao desenvolvimento do raciocínio clínico; discussão das possibilidades diagnósticas; a elaboração de um planejamento de investigação e de cuidados ao paciente perante as hipóteses levantadas, identificando lacunas de conhecimento, realizando as buscas necessárias e compartilhando as informações encontradas pelo grupo.

Entre as atividades pedagógicas do internato, a sistematização do processo de ensino e aprendizagem é desenvolvida pelo ciclo pedagógico. Esse ciclo é desenvolvido em encontros semanais entre os internos e preceptores responsáveis por esta atividade didática (não necessariamente representados por preceptores que acompanham os diversos estágios do internato) e se baseia na realização do Portfólio Reflexivo.

Esse portfólio, utilizado como um instrumento de reflexão da prática, busca a construção do conhecimento e do desenvolvimento pessoal e profissional dos envolvidos, facilitando a autoavaliação e a avaliação realizada pelo professor do ciclo. Em sua realização, o estudante desenvolve as seguintes tarefas avaliativas: narrativa reflexiva, síntese provisória, busca qualificada, nova síntese e avaliação ${ }^{11}$.

A narrativa reflexiva retrata a vivência individual, apresenta a reflexão sobre o fato, a reflexão sobre si mesmo e a relação com o desempenho. A síntese provisória sinaliza a síntese da vivência individual e grupal dos conhecimentos prévios e das lacunas de conhecimentos, levanta hipóteses e formula questões de aprendizagem e a avaliação dessa ação. A busca 
qualificada contempla a vivência individual da sistematização da busca realizada a partir de critérios qualificados de escolha das fontes; registra como o estudante responde às questões; traz o fichamento da fonte à referência. A nova síntese evidencia a síntese da vivência individual e grupal das respostas às questões de aprendizagem, com aprofundamento conceitual e científico; traz a relação do que foi estudado/apreendido com a prática com a intenção de transformá-la, e a avaliação dessa ação - avaliação do estudante (autoavaliação), avaliação do grupo e do processo?.

\section{OBJETIVO}

Avaliar a percepção dos estudantes de Medicina da Famema e de seus preceptores sobre a continuidade do processo de aprendizagem ativo na construção do conhecimento nas atividades do internato.

\section{PERCURSO METODOLÓGICO}

Esta pesquisa, atendendo aos procedimentos previstos na Resolução 196/96 do Conselho Nacional de Saúde, foi avaliada pelo Comitê de Ética em Pesquisa da instituição em que foi desenvolvida - CEP/Famema - e aprovado como processo $\mathrm{n}^{\mathrm{o}}$ 624/12. Ressalta-se, ainda, que não houve conflito de interesses nesta pesquisa.

Optou-se por um estudo de caso qualitativo, pois a análise de percepções e expectativas foi mais bem compreendida pela abordagem qualitativa ${ }^{12}$. Esta investigação contou com um universo de 160 internos (80 da quinta série e 80 da sexta série), além de 150 preceptores de internato. Na seleção dos participantes incluídos nesta pesquisa, os sujeitos foram sorteados de forma aleatória e representativa, e compostas por 10 estudantes da quinta série e 10 estudantes da sexta série dos diferentes grupos do internato, e outro sorteio, que foi composto por 25 preceptores dos diversos estágios do internato.

Incluíram-se no estudo alunos que cursavam a Famema desde a primeira série e os médicos que atuassem, no mínimo, por dois anos como preceptores nas atividades do internato e conhecessem a ABP.

A coleta dos dados foi realizada pela técnica de grupo focal, por se tratar de um instrumento informal para buscar informação, ter caráter flexível e permitir a interação entre os participantes.

O instrumento de coleta de dados foi a técnica de entrevista semiestruturada, pela necessidade de possibilitar a coleta dos dados, haja vista a heterogeneidade de atividades e horários disponíveis dos preceptores.

Perguntas norteadoras do grupo focal: (a) Como vocês constroem o conhecimento durante as atividades do internato?

(b) Qual a contribuição da Aprendizagem Baseada em Problemas nas atividades durante o internato?

(c) Quais as fragilidades e fortalezas encontradas no processo de ensino-aprendizagem durante o internato, levando-se em conta terem utilizado a ABP nos quatro primeiros anos?

Perguntas semiestruturadas para os preceptores:

(a) Como você desenvolve o processo de ensino e aprendizagem no internato com os estudantes?

(b) Qual o seu papel como preceptor no processo de construção do conhecimento dos internos?

(c) Os seus internos são egressos da ABP. Houve repercussão da $\mathrm{ABP}$ na realização das tarefas e busca de informações desses estudantes no internato?

$\mathrm{Na}$ análise dos dados utilizou-se a técnica de Análise de Conteúdo, segundo Bardin ${ }^{13}$, que divide a análise em três fases na análise temática:

Pré-análise - organização do material, ou seja, das falas transcritas selecionadas:

- leitura flutuante - contato inicial com os textos; gradativamente, a leitura tornou-se mais precisa em função da relação entre hipóteses iniciais, hipóteses emergentes e teorias relacionadas ao tema;

- constituição do corpus - organização do material, que contemplava algumas regras da validade qualitativa, como a representatividade da amostra estudada dentro do universo inicial, a homogeneidade das informações coletadas, a exaustividade de informações (falas) apresentadas e a pertinência de adequação do material apresentado enquanto fonte de informação para o objetivo do trabalho;

- formação de hipóteses e objetivos - levantamento de hipóteses acerca do que foi encontrado no material, o que possibilitou novas indagações acerca da temática; determinação da unidade de registro, que constitui um elemento representativo da mensagem retratada pelos textos; delimitação da unidade de contexto, representada por trechos significativos das falas; categorização dos elementos encontrados; e elucidação de fundo teórico para a realização da análise.

Exploração do material - operação de codificação que transformou os dados brutos em dados representativos do conteúdo das falas codificadas. A seguir, elencaram-se as ca- 
tegorias teóricas e empíricas responsáveis pela especificação do tema.

Interpretação dos resultados - buscou-se revelar o conteúdo, por meio de características dos fenômenos analisados.

$\mathrm{Na}$ análise, cada estudante foi representado da seguinte forma: quinta série: Q1, Q2... Q10; sexta série: S1, S2... S10; preceptores: P1, P2... P25.

\section{RESULTADOS E DISCUSSÃO}

A análise dos dados permitiu a construção de três categorias empíricas que abarcaram os núcleos de sentido dos preceptores e dos estudantes, e que serão discutidas independentemente a seguir.

\section{A ação pedagógica dos preceptores na construção dos conhecimentos dos internos: do comprometimento à interlocução com os sujeitos}

Na percepção dos estudantes, o comprometimento dos preceptores na construção do conhecimento é destacado no processo de ensino e aprendizagem pelo interesse de se colocarem à disposição para discutir os casos clínicos e os incentivarem na busca do conhecimento:

\footnotetext{
"Eles incentivaram a gente a buscar... e não só a aceitar o que eles estão falando". (Q5)

"Boa parte deles estimula, não dizem, não revelam as respostas completas, mas estimulam um raciocínio inicial para levantar, esclarecer melhor algumas dúvidas; geralmente, eles propõem discutir o assunto posteriormente". (S7)
}

Os estudantes revelam que as ações pedagógicas dos preceptores ocorrem pelo incentivo à busca de informações oriundas de dúvidas em discussões breves com eles, mas não expressam a organização dos passos da ABP, centrada no estudante e adaptada ao internato.

As ações desses preceptores são criticadas pelos estudantes:

"Estimular não é omitir informações e dizer para o aluno: "Ah, vá buscar!"; seria mais construtivo se ocorresse uma discussão... existe um caso clínico, existe uma dúvida, faça uma discussão, exponha alguns aspectos, mas não todos".

Essas atitudes não adaptam a $\mathrm{ABP}$ ao internato no processo pedagógico.

Segundo o Manual do Internato da Famema9 , os preceptores, no contexto de ensino e aprendizagem, devem reconhecer as lacunas de conhecimento dos estudantes e ajudá-los a elaborar os objetivos de aprendizagem, reconhecer seus próprios limites de conhecimento e participar do processo de aprendizagem, percebendo, conjuntamente com os internos, a relevância do problema ou ajudá-los a identificar, no pressuposto da interação de Vygotsky ${ }^{14}$, o que eles necessitam aprender. Entretanto, segundo a fala acima, esse auxílio se desenvolve de forma incipiente no processo pedagógico.

No processo de ensino e aprendizagem voltado para o estudante, os preceptores devem contribuir para a formação de indivíduos autônomos, responsáveis e participantes, conscientes de sua função social ${ }^{15}$. Entretanto, os preceptores, em alguns momentos, não desenvolvem o processo de ensino-aprendizagem ativo, já que muitas vezes não utilizam as recomendações dessa aprendizagem na potencialização do desenvolvimento cognitivo dos estudantes, e para estes fica a ideia de que:

"No quinto ano, isso ficou bem claro. Na maioria dos estágios, não tinha incentivo de querer ter discussão... poucas coisas foram proveitosas". (S10)

Por vezes, brainstorming, identificação de lacunas de conhecimento, elaboração das questões de aprendizagem, discussão da busca de informações, avaliação crítica dos artigos e sua aplicação são omitidos:

"Tento questionar sobre a conduta, pergunto o exame físico,
o que eles acham, o que eles fariam agora, eu tento fazer com
que eles pensem". (P12)

Outro ponto a destacar é a dificuldade que os preceptores manifestam em mudar suas posturas tradicionais no processo de ensino e aprendizagem:

\footnotetext{
“O PBL seria: você dá uma parte e ele vai ficar curioso e vai buscar, mas eu acabo falando tudo... eu acho que é porque a minha formação foi assim, eu aprendi assim com os meus professores". (P6)
}

Isto provoca um corte no processo de elaborar a construção da aprendizagem desenvolvida pelos estudantes nos quatro primeiros anos, dificultando a aquisição ativa do conhecimento.

Neste ponto, o processo de internalização, assimilação e acomodação ao qual esses preceptores foram expostos os impede hoje de iniciar um processo de mudança. A racionalização acima enunciada mostra o quanto o papel tradicional 
permanece presente nesses profissionais, mesmo após tantos anos de mudanças pedagógicas.

Esses preceptores têm dificuldades de romper com o modelo que vivenciaram em suas práticas prévias de aprendizagem, demonstrando a notória formação de tendência instrucionista, de difícil mudança por eles próprios. Isto dificulta e exige cuidado na capacitação desses profissionais para o entendimento metodológico da proposta da ABP.

Desta forma, alguns preceptores são frutos de outros modelos de formação, em que muitos confundem transmissão da informação com processo ativo de ensino e aprendizagem, mostrando, muitas vezes, despreparo para a preceptoria em processos ativos da formação profissional ${ }^{15}$.

As atividades do internato são baseadas em problemas, independentemente do modelo pedagógico. Por isso, muitos preceptores consideram que estão praticando a ABP. Nem sempre as atividades realizadas para resolver os problemas podem ser consideradas ABP. A diferença é a postura de docentes e discentes na resolução dos problemas - de passiva para ativa. Essa diferença é de difícil percepção e compreensão. Daí decorre a importância da capacitação permanente.

A participação em programas de capacitação docente e nas sessões de tutorias no papel de tutor ou cotutor, como facilitador da Unidade de Prática Profissional (UPP) e dos Laboratórios de Prática Profissional (LPP) das diferentes séries, é uma atividade destacada como necessária pelos preceptores:

\footnotetext{
"Nem todos os docentes têm conhecimento e treinamento para exercitar isso com eles... No início do PBL, nós tivemos muita capacitação para todo esse processo, nós tivemos vários cursos de avaliação, de preparação para as tutorias e tudo, e, hoje, essa capacitação parece estar muito paralisada dentro da instituição". (P13)
}

Tal fala ilustra as dificuldades de exercer a docência na ABP, destacando-se, então, a importância da educação permanente e continuada.

Outro ponto a destacar nessa categoria é a ação pedagógica e o cuidado que os preceptores desenvolvem com os pacientes, os quais se refletem nas escolhas e atitudes dos estudantes:

\footnotetext{
"Há estágios completamente desorganizados, com professores completamente inoperantes em relação ao processo de ensino-aprendizagem do aluno" (S9),
}

influenciando positiva ou negativamente as escolhas futuras desses estudantes. Além disso, estágios desorganizados e professores pouco estimuladores revelam a falta de compromisso com a formação dos estudantes. As razões disso requerem esclarecimentos.

Nesse ponto, a qualidade da relação médico-paciente é caracterizada pelos internos como de grande influência e referencial em sua formação profissional:

\begin{abstract}
"No internato tem contato com professor modelo, indivíduos que praticam a medicina de uma maneira que você se sente motivado a fazer como ele faz, da forma como ele se envolve com os pacientes; esse contato professor/aluno nos cenários reais de atividade é extremamente importante". (Q6)
\end{abstract}

Confirma-se, então, a importância do exemplo na formação ética dos futuros profissionais.

Outras vezes, as posturas não são adequadas ao cuidado dos pacientes e representam exemplos a não serem seguidos:

"[...] consegue aprender com os bons exemplos e também com os maus... você faz um balanço para ver como você vai querer se formar como médico". (Q4)

Essa observação desencadeia entre os estudantes a visão crítica em suas ações, pois acabam sendo reflexos dos modelos que observam:

"Passei pelo PS e continuei fazendo, continuei eu mesma, tratei meus pacientes bem, por mais que os profissionais que trabalham lá sejam diferentes". (Q10)

É a demonstração da capacidade de autonomia crítica e reflexiva e de atitude ativa que pode ser fruto do processo pedagógico e/ou própria dessa pessoa.

\section{A influência dos cenários, dos pacientes e das ações pedagógicas na construção do processo de ensino e aprendizagem no internato}

O âmbito dos cenários de ensino e aprendizagem do internato tem apresentado significativas dificuldades que preceptores e estudantes encontram ao se inserirem no contexto da assistência à saúde e no desenvolvimento do processo pedagógico:

\footnotetext{
"No quinto ano, você precisa dar conta da demanda do serviço, te traz para tocar o serviço lá; então, a discussão acaba ficando em segundo plano, se der tempo discute, se não, eles passam logo a conduta para dar seguimento à rotina normal do serviço". (S7)
}

Os preceptores relatam a dificuldade de os estudantes conciliarem o cumprimento de tarefas, a busca ativa de infor- 
mações e o desenvolvimento da aprendizagem perante a demanda do serviço de saúde:

"Pelo número de plantões, eles acabam estudando menos... acabam tendo falta de tempo para fazer isso aqui dentro".

Os preceptores também referem a dificuldade de conduzir o serviço de saúde pelo qual são responsáveis enquanto desenvolvem as ações pedagógicas com os estudantes:

\footnotetext{
“O ensino aprendizagem é baseado nos casos clínicos... aqui na enfermaria, pelo tempo, não dá pra gente ver muitas coisas, tem muito trabalho burocrático". (P3)

"Com essa correria aqui dentro, ou você dá assistência ou você se dedica mais a essa parte de ensino..." (P12)
}

A demanda do serviço é uma realidade incontestável, porém não é o fator principal da dificuldade de busca ativa de informações. Esta dificuldade revela a inexperiência em utilizar os passos da tutoria adaptados ao internato, o que demonstra a necessidade de repensar o currículo proposto no internato.

Nos cenários de ensino e aprendizagem, os preceptores devem construir espaços para exercer suas funções assistenciais e docentes segundo um conceito amplo de práticas, incorporando ações pedagógicas construtivistas e utilizando tecnologias e habilidades cognitivas e psicomotoras que constroem e transformam o ambiente de trabalho e de educação em saúde ${ }^{16,17}$. Ao serem inseridos nesses cenários, os internos devem interagir no ambiente de trabalho com o apoio necessário da instituição que o gerencia e receber auxílio dos diferentes profissionais nesta concepção.

Outro reflexo no internato é a importância do contato com a prática (o paciente) como motivador no processo de ensino e aprendizagem:

"O que mais estimula é o paciente dar um retorno para a pessoa que eu estou atendendo" (Q8),

em que o "P" da ABP deixa de representar o Papel do problema estruturado da tutoria e passa a representar o Paciente a ser cuidado.

Nesse cuidado, deve-se ater à escuta das queixas do paciente para identificar suas necessidades de saúde, levantando dúvidas após um breve brainstorming (das queixas, sinais e sintomas) e elaborando questões norteadoras de aprendizagem. Após as hipóteses diagnósticas (que se somam a outros recursos complementares de diagnóstico) e a busca de respos- tas qualificadas (propostas terapêuticas), organizam, então, o cuidado integral e individual, em conjunto com o trabalho da equipe multiprofissional.

Logo, a postura proativa deve ser a base da atuação dos estudantes em sua futura prática profissional. A motivação e o estímulo à aprendizagem devem ser percebidos pelo estudante como relevantes para sua prática e cuidado com os pacientes $^{18,19}$ :

\footnotetext{
"Nossa angústia interna é muito maior do que os estímulos dos professores; eles fazem a parte deles, estimulam, mas você fica numa angústia, porque, a todo momento, você vê um caso que você não sabe..." (S8)
}

Nesse momento, destacamos que, para ser proativo na busca de informações, o estudante deve saber procurar artigos válidos, importantes e aplicáveis. Para que essa angústia seja modificada, os passos da tutoria devem ser adaptados ao internato. Trata-se de uma ação pedagógica que não requer tempo prolongado.

No processo de ensino e aprendizagem, durante o internato, os estudantes destacam a importância do ciclo pedagógico na construção do conhecimento:

"[...] discutia, abria as questões e voltava com o estudo para discutir de novo as hipóteses que a gente abriu, para ver se era mesmo ou não".

Na concepção dos preceptores, esse ciclo é entendido como:

"[...] nos ciclos do quinto ano na Pediatria, eles trazem os ca-
sos para discutir... fazem as discussões, fazem um brainstorm
ali, num primeiro momento, depois a gente faz as questões
de aprendizado, vai para a pesquisa e volta para responder às
questões". (P24)

O ciclo pedagógico deve propiciar a oportunidade para um processo reflexivo organizado e continuado. É um espaço de questionamento sistemático sobre as situações do trabalho, que levam ao desenvolvimento de habilidades de autoavaliação e de autoconhecimento do estudante ${ }^{9}$. Entretanto, como é realizado distante das atividades práticas do internato, em espaços constituídos (agendados), não envolve a dinâmica das interações entre os sujeitos ${ }^{14}$.

Em vista das propostas, as ações desenvolvidas pelos internos devem ser objeto de reflexão, pois é na reflexão sobre as práticas desenvolvidas, avaliadas e continuamente revisadas 
que se reconstrói o conhecimento prévio, numa perspectiva integradora dos referenciais teóricos e da prática profissional. Isto se torna possível quando se avalia a competência profissional por meio de desempenho demonstrado pelos internos na realização das tarefas ${ }^{13}$.

\section{A ABP e o internato na Famema: o reflexo do processo pedagógico ativo na construção dos conhecimentos e na formação dos estudantes}

Os internos destacam as seguintes percepções acerca da contribuição que a ABP trouxe para o processo de ensino e aprendizagem durante o internato:

"É possível, sim, fazer o processo de ensino e aprendizagem no quinto e no sexto anos; a gente aprendeu, desenvolveu o raciocínio clínico, conseguiu desenvolver certos planos terapêticos, conseguiu amadurecer para minimamente tentar ser um bom profissional". (S4)

Essa mesma percepção está presente nas falas dos preceptores:

"Os alunos do PBL chegam bem preparados no internato, eles dão um feedback melhor... sabem formular uma hipótese diagnóstica". (P9)

"Eles conseguem resgatar conhecimentos anteriores e fazer um raciocínio clínico". (P12)

O propósito desencadeado pela $\mathrm{ABP}$ - em que se favorece a aquisição e a estruturação adequada do conhecimento num contexto de situações-problema, facilitando a ativação e a utilização posterior de informações - é demonstrado no desenvolvimento pedagógico dos estudantes por essas falas.

A ABP, quando realizada seguindo integralmente os passos da tutoria, promove a participação ativa dos estudantes na construção de seus conhecimentos. A mola propulsora é a identificação das lacunas de conhecimento, transformadas em questões de aprendizagem, que constituirão o conteúdo a ser pesquisado. $\mathrm{O}$ estudante é movido por sua curiosidade para o aprendizado e o desenvolvimento de habilidades para a autoaprendizagem, tornando o aprendizado uma ação ativa, desencadendo a busca do conhecimento para a resolução de problemas e a constituição da aprendizagem de adultos. Nesse momento, o estudante deixa de ser passivo e desempenha um papel preponderante em sua formação, como identificado nas falas acima ${ }^{9,18}$.

A ABP, seguindo os passos da tutoria, estimula o estudante na tomada de decisão sobre como e o que aprender. $\mathrm{O}$ "em- poderamento" (empowerment) trazido pelo estudante pela responsabilidade sobre o próprio aprendizado é uma habilidade extremamente útil, uma vez que, quando o estudante chegar ao fim do curso, metade do que aprendeu estará desatualiza$\mathrm{da}^{9}$. Logo, ele necessita ser proativo em buscar, ser questionador na busca de suas informações:

$$
\begin{aligned}
& \text { "[...] eles são mais reflexivos, é um estudante ativo, ele busca } \\
& \text { quando tem dúvida, ele questiona, é um aluno que questiona } \\
& \text { mais..." (P19) } \\
& \text { "[...] a gente procura em mais lugares e não em uma fonte } \\
& \text { unica, não confia muito na opinião de um único especialista, } \\
& \text { por melhor que ele seja". (Q2) }
\end{aligned}
$$

Essas falas revelam que a internalização realizada nos primeiros quatro anos da graduação permite que o estudante, mesmo sob uma rotina restritiva do estágio que está realizando, perceba que o conhecimento tem uma amplitude muito maior do que aquela em que ele está imerso. Mesmo não conseguindo buscar naquele momento da aprendizagem, ele duvida e não acredita cegamente nas informações apresentadas pelos preceptores.

Os estudantes assumem a responsabilidade sobre a própria aprendizagem na ABP sob a seguinte ótica:

\footnotetext{
“O ponto positivo do PBL é que acabei aprendendo a me virar com o estudo, a gente fica independente, vai atrás das coisas que acha importantes, e o que não acha importante acaba sendo irrelevante..." (S7)

"Eles sabem pesquisar muito bem, eles sabem buscar a informação, eles procuram vir com informações atualizadas, de várias fontes". (P13)
}

Destaca-se, porém, nestas falas, a falta de dados - passos da tutoria, como levantamento da dúvida, elaboração da questão de aprendizagem, discussão da estratégia de busca e análise crítica da literatura encontrada - para dizermos que os internos constroem a ABP centrada no estudante. Mostram, essencialmente, que são autônomos na construção do conhecimento durante o internato, diferentemente da proposta interacional entre os sujeitos que constroem o conhecimento.

A habilidade de buscar a informação para sustentar a habilidade de estudo autodirigido é essencial ao desempenho profissional futuro do estudante ${ }^{9}$. Os estudantes devem desenvolver a habilidade de obter a informação quando ela é necessária e se atualizar constantemente.

Os entrevistados destacam, entretanto, a dificuldade encontrada em resgatar conhecimentos de áreas básicas na 
construção dos diagnósticos clínicos, elucidando a deficitária construção dos conhecimentos destas áreas durante os quatro primeiros anos da graduação:

"A metodologia ativa para o internato é válida, mas traz deficiências em termos de matérias básicas, dos primeiros anos de faculdade". (Q2)

A mesma opinião é compartilhada entre os preceptores:

"Eles têm déficits em algumas coisas básicas, e a gente precisa reforçar isso porque, na hora em que você vai examinar alguém, precisa saber exatamente o que está procurando". (P1)

Na dificuldade de resgatar conhecimentos de áreas básicas ou construir o conhecimento destas áreas, os estudantes revelam o não entendimento da proposta do processo de ensino e aprendizagem preconizada pela Famema, na qual o conteúdo é determinado pela necessidade e pelos objetivos de aprendizagem do estudante, sendo mais importante o "aprender a aprender".

$\mathrm{Na}$ ABP, o estudante deve identificar as lacunas do conhecimento (os conteúdos necessários à construção de sua aprendizagem) como parte de um contexto articulado de fenômenos que deverá ser visualizado, objetivado, refletido por um ângulo centrado no paciente, com base na proposição de um problema real. Ele, então, pode fazer a busca do conhecimento de áreas básicas que não fez nos primeiros quatro anos da graduação no momento em que necessita resolver sua dúvida ${ }^{9,10,18}$.

Nesse contexto, tem-se que a ABP guarda a proposição básica de que a aprendizagem deixa de ser centrada no professor para enfatizar o aprendizado ativo dos estudantes, o que solicita destes atenção, questionamento, leitura, busca ativa por informações científicas e síntese de conteúdos ${ }^{9,10,18}$.

Desta forma, o reflexo construtivista da ABP se faz presente na elaboração do conhecimento entre os estudantes para desenvolver em sua formação a habilidade de comunicação, o trabalho em equipe, a solução de problemas, o respeito aos colegas e o desenvolvimento de postura crítica. O desenvolvimento dessas habilidades e o domínio de conhecimento de situações práticas trazem aos futuros médicos mais capacidade de lidar com os problemas da vida profissional, tornando-os capazes de observar, escutar, pensar, saber ser, fazer e aprender.

Nesse sentido, iniciam-se processos, constroem-se sujeitos sociais que passam a dar conta dos desafios impostos por essa nova realidade, e a formação de recursos humanos e a educação médica em particular, ainda que não exclusivas, passam a ser importantes espaços de constituição desses sujeitos ${ }^{17}$.

\section{CONCLUSÃO}

Os resultados da pesquisa demonstram a dificuldade de continuar o processo de aprendizagem ativo no internato na perspectiva da ABP voltada para os estudantes e pacientes, por parte tanto dos professores como dos estudantes.

A maioria das respostas dos preceptores e dos internos às questões norteadoras aponta que não há pleno entendimento do processo pedagógico da Famema, cujo currículo é integrado, orientado por competências num processo de aprendizagem que se realiza com participação ativa dos sujeitos envolvidos.

A discussão dos problemas dos pacientes e a busca de informações são realizadas nos moldes do ensino tradicional, mas deveriam ocorrer no internato diariamente com os preceptores que supervisionam as tarefas nas vivências da prática médica.

Quando realizam as tarefas do internato, os preceptores e estudantes não utilizam os passos da ABP de forma individualizada e em grupos, como nas primeiras quatro séries do curso. Destaca-se, então, a importância da experiência do preceptor de ter sido ou estar em contato com tutores.

Há, também, a solicitação de continuidade do processo de capacitação pelos preceptores, com a necessidade de resgatar a educação continuada e permanente em todos os cenários do internato.

Assim, fica evidente a necessidade de mudança de postura. O entendimento do processo pedagógico não está acontecendo gradativamente nessas atividades, criticando, refletindo e estudando, da prática para a teoria. Os preceptores, assim como os estudantes, são pouco ativos no processo de ensino e aprendizagem, e a Famema, enquanto instituição formadora, traz para si a necessidade de rever a organização curricular do internato no contexto amplo e democrático da formação de um processo ativo de ensino e aprendizagem.

\section{REFERÊNCIAS}

1. Cristoffanini AP. El internado em los estudios medicos. Educ Méd Salut. 1982;16(2):134-50.

2. Associação Brasileira de Educação Médica. O internato nas escolas médicas brasileiras. Rio de Janeiro: ABEM; 1984.

3. DemarzoI MMP, Fontanella BJC, Melo DG. Internato longitudinal. Rev Bras Educ Méd. 2010;34(3):430-7.

4. RuizI DG, FarenzenaII GJ, Haeffner LSB. Internato regional e formação médica: percepção da primeira turma pós-reformacurricular. Rev Bras Educ Méd. 2010;34(1):21-7.

5. Bouhuijs PAJ, Schmidt HG, Van Berkel HJM. Problem-based learning as an educational strategy. Maastricht: Network Publications Maastricht; 1993. 
6. Brasil. Ministério da Educação. Conselho Federal de Educação. Resolução n. 9, de 24 de maio de 1983. Regulamenta o internato dos cursos de medicina. Diário Oficial da União, Poder Executivo, Brasília (DF); 30 maio 1983. Seção 1:9.

7. Brasil. Ministério da Educação. Conselho Nacional de Educação. Câmara de Educação Superior. Resolução CNE/CES n. 4, de 7 de novembro de 2001. Institui Diretrizes Curriculares Nacionais do Curso de Graduação em Medicina. Diário Oficial da União, Brasília (DF); 9 nov 2001. Seção 1:38.

8. StreitI DS, Maciel DT, Zanolli MB. Contribuição para a formação de médicos de acordo com as necessidades da sociedade: interação com as políticas de articulação ensino, serviço, sociedade implementadas pelo ministério da saúde. Cad ABEM. 2009;5:21-9.

9. Faculdade de Medicina de Marília. Manual do Internato. In: Tsuji H, Zanolli MB, coordenadores. Marília: Faculdade de Medicina de Marília; 2003.

10. Chaves ITS, Grosseman S. O Internato médico e suas perspectivas: estudo de caso com educadores e educandos. Rev Bras Educ. Méd. 2007;31(3):212-22.

11. Savin-Baden M. The problem-based learning landscape. Planet. 2004;(4):4-6.

12. Yin RK. Estudo de caso: planejamento e métodos. Porto Alegre: Bookman; 2010.

13. Bardin L. Análise de conteúdo. Lisboa: Edições 70; 1997.

14. Alves WF. A formação de professores e as teorias do saber docente: contextos, dúvidas e desafios. Educ Pesqui. 2007;33(2):263-80.

15. Missaka H. A prática pedagógica dos preceptores do internato em emergência e medicina intensiva de um serviço público não universitário. Rio de Janeiro; 2010. Mestrado [Dissertação] - Universidade Federal do Rio de Janeiro.
16. Schilling C. Domínios do conhecimento, prática educativa e formação de professores: a construção do conhecimento escolar. São Paulo: Ática; 1998.

17. Nogueira MI. As mudanças na educação médica brasileira em perspectiva: reflexões sobre a emergência de um novo estilo de pensamento. Rev Bras Educ Méd. 2009;33(2):262-70.

18. Barrows HS, Tamblyn RM. Problem-based learning: an approach to medical Education. New York (NY): Springer; 1980.

19. Barrows HS. Practice-based learning: problem-based learning applied to medical education. Springfield: Southern Illinois University School of Medicine; 1994.

\section{CONTRIBUIÇÃO DOS AUTORES}

Os Autores Ricardo Correa Ferreira, Hissachi Tsuji e Silvia Franco da Rocha Tonhom participaram de forma equânime e suficiente na concepção e desenho do estudo "Aprendizagem Baseada em Problemas no Internato: há continuidade do processo de ensino e aprendizagem ativo?", analisando e interpretando os dados, assim como na redação deste texto, para assumirem a autoria e a responsabilidade pública pelo conteúdo deste artigo. Revisaram e a versão final deste artigo e o aprovaram para ser encaminhado a publicação.

\section{CONFLITO DE INTERESSES}

Os autores declaram não haver conflito de interesses.

\section{ENDEREÇO PARA CORRESPONDÊNCIA}

Ricardo Correa Ferreira

Rua Laurindo Fontana, 166

Jd. Portal do Sol - Marília

CEP 17519-390 - SP

E-mail: riguaira@famema.br 